\title{
New Mutant Mouse with Skeletal Deformities Caused by Mutation in Delta Like 3 (DII3) Gene
}

\author{
Yusuke SHINKAI, Takehito TSUJ I, Yasuo KAWAMOTO, and Tetsuo KUNIEDA
}

\begin{abstract}
Graduate School of Natural Science and Technology, Okayama University, Tsushima-naka,
\end{abstract} Okayama, Okayama 700-8530, Japan

\begin{abstract}
We have established a new mouse strain with vertebral deformities caused by an autosomal single recessive mutation (oma). The mutant mice showed short trunk and short and kinky tail. The skeletal preparations of newborn and prenatal mice showed disorganized vertebrae and numerous vertebral and rib fusions which are thought to be caused by patterning defects at the stage of somitegenesis. Linkage analysis localized the oma locus on the proximal region of mouse chromosome 7 close to DII3 gene. DII3 is the gene involved in the Notch signaling pathway and null-mutation of the gene has been reported to cause vertebral deformities. The phenotypic similarity between oma and DII3 null-mutant mice suggests that the causative gene for the oma mutant is the DII3 gene. We, therefore, investigated the nucleotide sequence of the DII3 gene of the oma mouse and found a single nucleotide substitution of $G$ to $T$ which causes missense mutation of glycine to cysteine at codon 409. Since the amino acid substitution is a nonconservative amino acid substitution at the conserved portion of the DII3 protein, and the substitution is specific to the mutant mice, we concluded that the nucleotide substitution of the DII3 gene is responsible for the skeletal deformities of the oma mouse.
\end{abstract}

Key words: DII3, mutant mouse, SCD, somitegenesis, vertebral deformity

\section{Introduction}

Congenital abnormalities in formation of vertebrae have often been observed in various species of mammals including human and mouse. Particularly, a number of mutant mouse strains showing vertebral abnormalities have been reported. These mutant strains include brachyury [18], tail-short [28], undulated [12], curly-tail [14], crinkly-tail [23], meander tail [19], truncate [31], pudgy [16], tail kinks [15], and flexed-tail
[20], which are useful animal models for investigating the developmental mechanisms of vertebral formation. For example, brachyury $(T)$ is the classical mutant mouse showing tailless phenotype, which is associated with chromosomal inversion [30]. The causative gene for brachyury has been identified as an essential gene in mesoderm formation and thus this mutant mouse has been an excellent tool for studying processes underlying mesoderm formation in the mammals [18]. Many other genes controlling vertebral formation of mam-

(Received 4 August 2003 / Accepted 7 January 2004)

Address corresponding: T. Kunieda, Graduate School of Natural Science and Technology, Okayama University, Tsushima-naka, Okayama, Okayama 700-8530, Japan 
mals have been identified by investigating mutant mouse strains $[12,25]$. Furthermore, various knockout mice with targeted disruption of particular genes showing skeletal abnormalities have been reported [10, 22, 24, $33,34]$. These spontaneous and induced mutant mice could be good tools for studying molecular mechanisms of vertebrae formation, and these mutants could also be good animal models for human congenital abnormalities of vertebrae including spondylocostal dysostoses (SCD) which is characterized by multiple vertebral segmentation defects and rib anomalies [6].

We have established a new mutant mouse strain with vertebral and rib deformities. This mutant strain is originated from a male mouse with short trunk and short and kinky tail which appeared in a mouse colony maintained at Okayama university. The colony was derived from a multicross-hybrid of four different inbred strains. In this paper, we describe the morphological features of the mutant mouse, the chromosomal localization of the mutant locus, the sequence analysis of the candidate gene, and the identification of the causative mutation for the vertebral deformities.

\section{Materials and Methods}

\section{Mutant mouse strains}

The mutant mice are originated from a mouse colony derived from multicross-hybrids of C57BL/ $6 \mathrm{~J}, \mathrm{C} 3 \mathrm{H}$, $\mathrm{DBA} / 2$, and $\mathrm{BALB} / \mathrm{c}$ strains maintained at Okayama University. The mouse colony has been selectively bred for their high aggressive behaviors. During the selective breeding, a male mouse with short trunk and short and kinky tail appeared in 19th generation and mating between the sister and brother of the same litter again delivered mice with same phenotype. We, then, started to establish a congenic strain carrying the mutation by introducing the mutation into the C57BL/6J strain with sequential backcrossing. Currently, 14 generations of backcrossing have been completed.

\section{Skeletal preparations}

Skeletons of newborn mice were fixed with ethanol, stained with Alizarin Red and Alcian Blue, cleared by $\mathrm{KOH}$, and stored in glycerol as previously described [21]. Photographs were taken under a stereomicroscope with translucent light conditions.

\section{Linkage analysis}

To determine the chromosomal localization of the mutant locus by linkage analysis, $\mathrm{F}_{1}$ mice were generated by mating between homozygous mutant and JF1/ Ms mice and, subsequently, backcross progeny of 76 mice were obtained by mating between the $\mathrm{F}_{1}$ and homozygous mutant mice. High-molecular weight genomic DNAs were prepared from the livers of the backcross mice by phenol-chloroform extraction.

Eight microsatellite markers on mouse chromosomes 5 and 7 were typed by PCR using primers for these markers followed by electrophoresis through 3\% agarose gels. PCR amplification was carried out for 35 cycles consisting of denaturation at $94^{\circ} \mathrm{C}$ for $30 \mathrm{~s}$, annealing at 50 to $65^{\circ} \mathrm{C}$ for $30 \mathrm{~s}$, and extension at $72^{\circ} \mathrm{C}$ for $30 \mathrm{~s}$. The reaction mixture of $10 \mu \mathrm{l}$ contained 0.2 $\mu \mathrm{M}$ of each primer, $0.25 \mathrm{U}$ of Taq polymerase (Gibco BRL, Gaithersburg, MD, USA), $0.2 \mathrm{mM}$ of each dNTP, Taq buffer containing $1.5 \mathrm{mM} \mathrm{Mg}^{2+}$ and $20 \mathrm{ng}$ of mouse genomic DNA. Linkage analysis was performed using Map Manager QT Ver. 3.0 software [27].

\section{Sequencing analysis of the Dll3 gene}

The entire coding region of the Dll3 gene was amplified from genomic DNA of normal and mutant mice with 7 pairs of primers corresponding to exons 2 to 10 of the gene. The PCR condition was same as that for the microsatellite markers. The nucleotide sequences of the primers are: ATAAGACTCCGGCATCCAGCAGC and CGCTGTAAAGCGTATTCGTG (exons2 and 3), GCTGGGA T TACAGGTATGTGC and ATCCAAAACCACTAGCCCAGC (exon4), GA T GA C C T GA A T C T CA G T GC and ATCCGCGCTTAAGTAGTAGC (exon5), TCCCAACCTGCTCTAGCATTC and GTCTACAGAGTGAGTTCTAGC (exon6), AAGGAGTCTCTTGCCCAAAGC and TCTGTCACCAGTCTGTTCTGG (exon7), AGTAGAAAAGACACAAGTGGGTGC and TCAGGTTGTTGAGTGCATCC (exon8), A C TCTTGGTCATCCACGTTCG and AATCATTCAGGCTCCATCTCCAG (exons9 and 10). The nucleotide sequences of these primers were obtained from EMBL/GenBank accession number AF068865. The amplified fragments were cloned into pGEM-T Easy Vector (Promega, Madison, Wis., USA) and their nucleotide sequences were determined by the 
Table 1. Segregation and reproductive data obtained during breeding of the oma mouse

\begin{tabular}{|c|c|c|c|c|c|c|}
\hline \multicolumn{2}{|c|}{ Parents } & \multicolumn{3}{|c|}{ Progeny } & \multirow{2}{*}{$\begin{array}{c}\text { No. of } \\
\text { Parturition }\end{array}$} & \multirow{2}{*}{$\begin{array}{c}\text { Mean } \\
\text { litter size }\end{array}$} \\
\hline Dam & Sire & Normal & Mutant & Total & & \\
\hline heterozygote $(\mathrm{oma} /+)$ & homozygote (omaloma) & 58 & 51 & 109 & 13 & 8.4 \\
\hline homozygote (oma/oma) & heterozygote $(\mathrm{oma} /+)$ & 52 & 64 & 116 & 15 & 7.7 \\
\hline heterozygote $(\mathrm{oma} /+)$ & heterozygote $(\mathrm{oma} /+)$ & 80 & 31 & 111 & 17 & 6.5 \\
\hline homozygote (omaloma) & homozygote (omaloma) & 0 & 89 & 89 & 16 & 5.7 \\
\hline
\end{tabular}

A

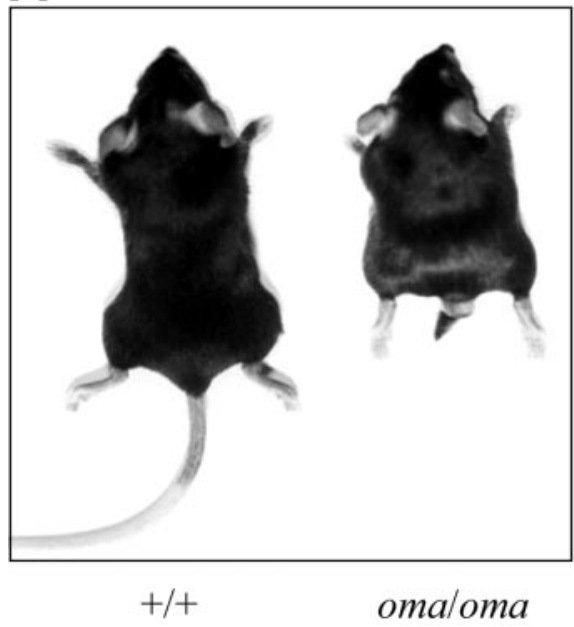

B

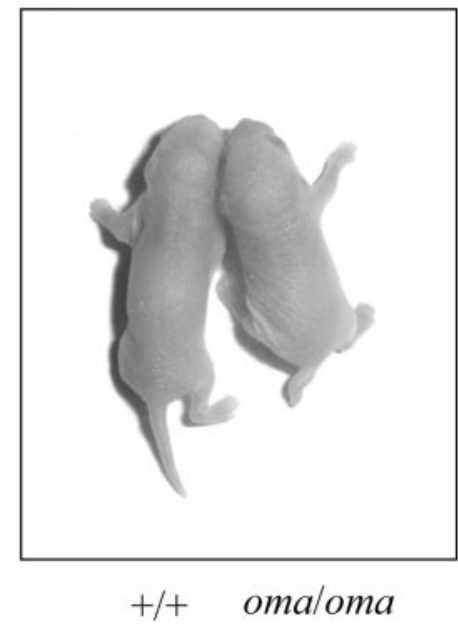

Fig. 1. External appearance of normal (left) and mutant (right) mice at 7 weeks old (A) and newborn (B) stages.

dideoxy chain terminating method with an automated DNA sequencer Hitachi SQ5500.

\section{Results}

\section{Mode of inheritance}

The segregation profile obtained during breeding of the mutant mouse strain showed that the vertebral abnormality is inherited in an autosomal single recessive manner. As shown in Table 1, crosses of homozygous mutant mice with heterozygous mice yielded $115 \mathrm{mu}$ tant and 110 normal mice and crosses between heterozygous mice yielded 31 mutant and 80 normal mice. Furthermore, no normal mouse was obtained from crosses between mutant mice and no sex ratio difference was observed in the progeny. The segregation data are concordant with the expected Mendelian ratio, indicating that the phenotype is controlled by an autosomal single recessive gene with complete pen- etrance. We tentatively designated the mutant locus oma (omagari). It should be noted that despite their serious skeletal abnormalities, both male and female homozygous mice are fertile and no increased embryonic or neonatal mortality of homozygous mice was observed.

\section{Morphological analysis of the mutant mouse}

External appearance of the omaloma homozygous mutant mouse is characterized by short trunk and short and kinky tail (Fig. 1). The short and kinky tail is apparent and body size is smaller than normal at the newborn stage (Fig. 1). The skeletal preparation of adult mice showed that the axial skeleton of the omal oma mouse was bent and severely disorganized with numerous vertebral and rib fusions and incompletely formed vertebrae (Fig. 2). Despite serious anomalies of vertebrae and rib, the mutant mice showed no obvious abnormality in the long bones of limbs and the 
A
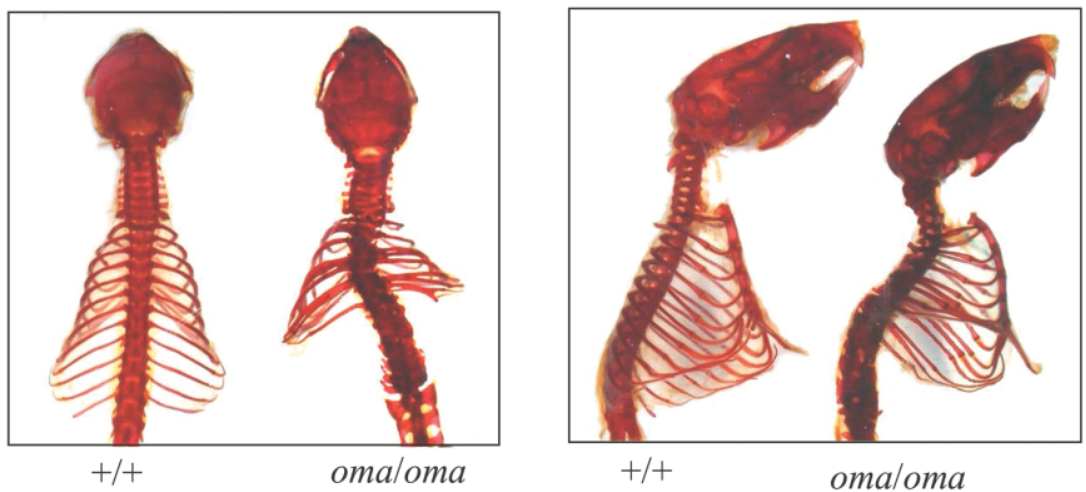

B

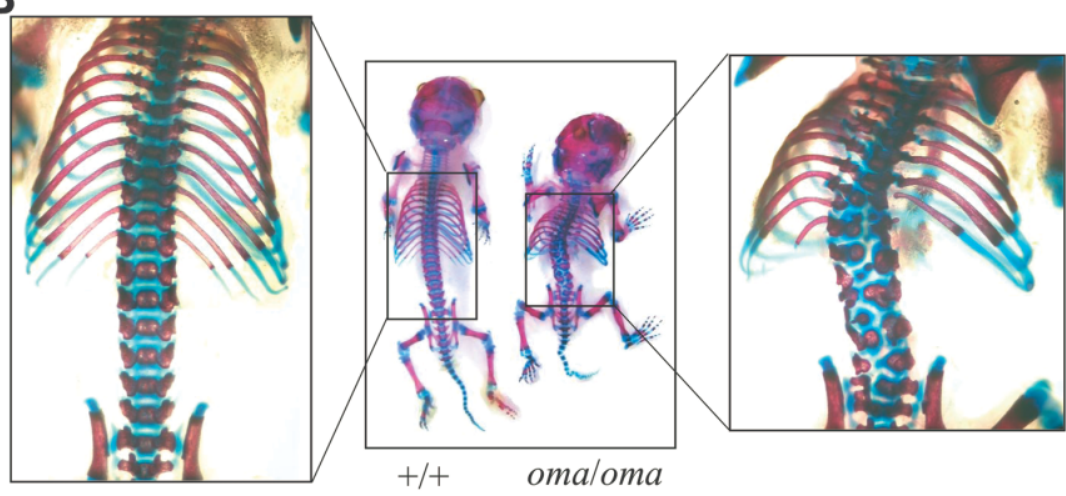

C

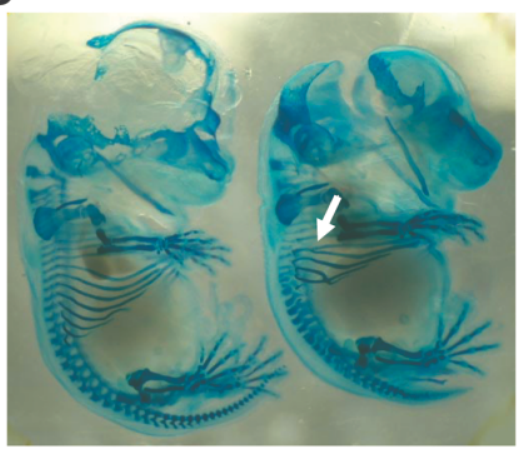

$+/+$

omaloma

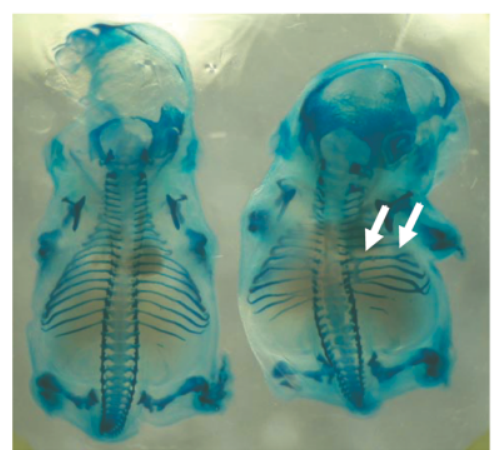

$+/+$

omaloma

Fig. 2. Skeletal preparations of adult, newborn, and prenatal mice. (A) Alizarin Red stained skeletons of adult mice; (B) Skeletal preparation of 1 day old newborn mice stained with Alizarin Red and Alcian Blue and the magnified photos on the left and right sides; (C) Alcian Blue stained mouse embryos at 14.5 dpc. Arrows show fusion and branching of the ribs of the mutant mouse.

skull. As shown in Fig. 2, the skeletal anomalies were apparent in vertebrae and rib of newborn mice and preskeletal cartilage of embryos at $14.5 \mathrm{dpc}$. In the skeletal preparation of a newborn mouse, insufficient and disorganized ossification patterns were observed in thoracic and lumbar vertebrae. Apparent segmentation defects were also observed in these vertebrae. In the 14.5 dpc embryos, the skeletal abnormality extended from most anterior vertebra to the end of the vertebral column and the vertebral arches surrounding the spinal 
cord were highly disorganized. These morphological features of the mutant mice indicated that the skeletal abnormalities of the mutant mouse are caused by malformation of vertebrae and suggest that the principal lesion of the mutant phenotype is a defect in formation and segmentation of sclerotome which gives rise to axial skeleton.

\section{Chromosomal mapping of oma locus}

The morphological features of the omaloma mice suggest that the skeletal anomaly of mutant mouse is caused by a defect of the gene(s) associated with segmentation of the axial skeleton. Since the Notch signaling pathway plays an important role in segmentation of axial skeleton and vertebral formation, the genes involved in the Notch signaling pathway are potential candidate genes for the oma mutation. Particularly, null mutations of Delta-like 3 (Dll3) and Lunatic fringe ( $L f n g$ ) genes in mice have been reported to cause segmentation defects of the vertebrae, which resemble those of the omaloma mice. The Dll3 and Lfng genes are localized on mouse chromosomes 7 and 5, respectively. We performed linkage analyses of the oma locus using microsatellite markers on mouse chromosomes 5 and 7 , to determine whether or not these genes are responsible for the oma mutant. As a result, significant linkage was observed between the oma locus and microsatellite makers on the proximal region of chromosome 7. As shown in Fig. 3, no recombination between the oma locus and the D7Mit77, D7Mit266, and D7Mit72 markers was observed in the backcross mice. The localization of D7Mit266 is close to Dll3 gene on chromosome 7 suggesting that mutation in the $D l l 3$ gene is responsible for oma mice.

\section{Sequence analysis of the Dll3 gene}

We, therefore, determined the nucleotide sequences of the Dll3 gene and compared the sequence between oma and normal mice. As shown in Fig. 4, the Dll3 gene comprises 10 exons, and exons 2-10 correspond to the coding region of the gene. These 9 exons were amplified by PCR using primers flanking the exons. No difference in lengths of the amplified fragments were observed between the mutant and normal mice (data not shown) indicating that the mutant allele has no gross change of nucleotide sequence including insertion or deletion of a large DNA segment in the gene.

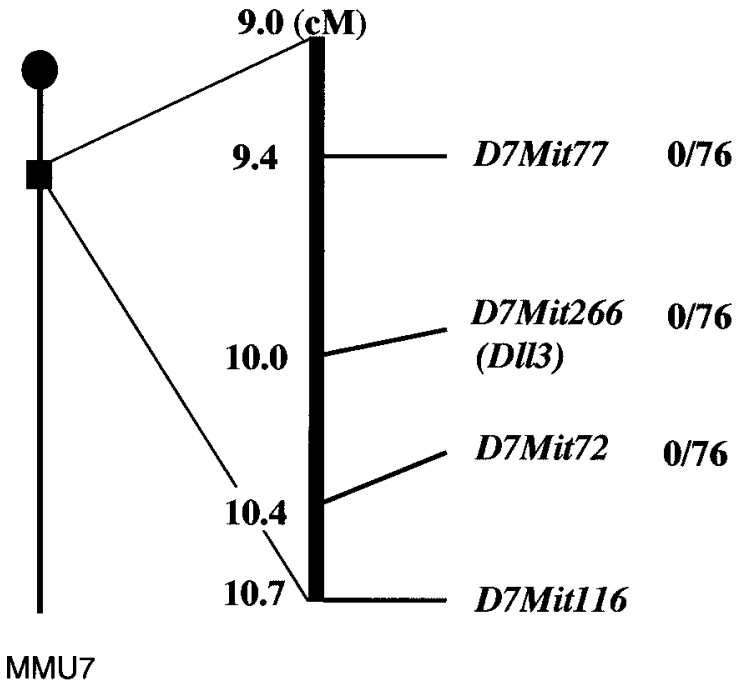

Fig. 3. A linkage map of the proximal region of mouse chromosome 7. Numbers on the right indicate the number of recombinants per backcross progenies. Numbers on the left of the linkage map indicate distances from the centromere in centi Morgans. The location of the microsatelite markers was obtained from the published linkage map (http://www.informatics.jax.org/).

Next, we cloned the amplified fragments of the mutant and normal mice and determined their nucleotide sequences. Comparison of the nucleotide sequences between the mutant and normal mice revealed a single base substitution in exon 8 (Fig. 4) which causes an amino acid substitution of glycine to cysteine at amino acid residue 409. To eliminate the possibility that the nucleotide substitution is a polymorphism among the inbred strains which give rise to the mutant, we determined the nucleotide sequence of the exon 8 of the gene in the four inbred strains. As a result, this substitution was not found in the ancestral strains of C57BL/6J, $\mathrm{DBA} / 2, \mathrm{BALB} / \mathrm{C}$, and $\mathrm{C} 3 \mathrm{H} / \mathrm{He}$.

\section{Discussion}

In the present study, we found a single base substitution in which an amino acid substitution of glycine to cysteine in the Dll3 protein takes place. Several lines of direct and indirect evidence indicate that this substitution is a causative mutation of the skeletal deformities of the mutant mouse. Firstly, association between the nucleotide substitution and the phenotype was confirmed by linkage analysis and the comparison of 


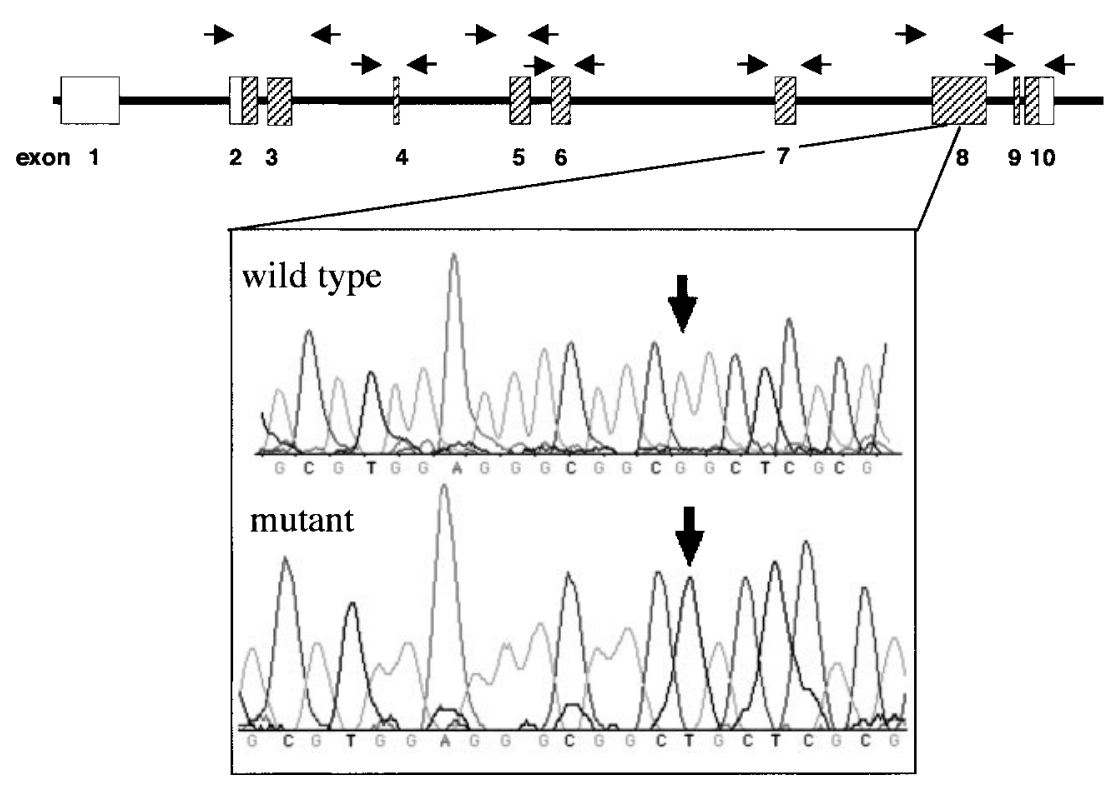

Fig. 4. Chromatograms showing a nucleotide sequence of exon 8 and genomic structure of the mouse Dll3 gene. Open boxes represent 5' and 3' non-coding regions and hatched boxes represent coding region. Horizontal arrows indicate positions of the primers which amplify the entire coding region of the gene. Vertical arrows in chromatograms denote the nucleotide substitution of $\mathrm{G}$ to $\mathrm{T}$ at codon 409 .

nucleotide sequences between the mutant mice and the four ancestral inbred strains. These findings indicate that the substitution is specific to the mutant and not a polymorphism among the inbred strains. Secondly, the phenotypes of omaloma resemble those of the spontaneous null-mutation (Dlll $\left.3^{p u}\right)$ [25] and knockout mice $\left(D l l 3^{\text {neo }}\right)[8]$ of the Dll3 gene. These spontaneous and induced mutants showed vertebral deformities indistinguishable from these of the omaloma mouse suggesting that the phenotypes of these three mutant mice are caused by a common molecular lesion. Thirdly, the amino acid substitution might have particular effects on the structure and function of the Dll3 protein. The Dll3 protein has six EGF-like domains in the extracellular portion of the protein and the amino acid substitution occurs in the 5th EGF-like domain. In each domain, six cysteine residues, which have important functions for domain structure by forming disulfide bonds, are highly conserved and there is no other cysteine residue in the domains. Therefore, the amino acid substitution which resulted in the appearance of a new cysteine residue inside the EGF-like domain might affect the structure of the Dll3 protein. Furthermore, the glycine residue in the 5th EGF-like domain is con- served among human, rat and mouse Dll3 proteins. Although both glycine and cysteine are positively charged amino acid, these two amino acids are not grouped into structurally equivalent residues [4] and missense mutations of particular genes causing substitutions of glycine to cysteine has been reported to be responsible for various human inheritable diseases [13, 17, 26, 29]. Although genetic complementation tests between oma and $\mathrm{Dlll}^{\mathrm{pu}}$ or $\mathrm{Dll} 3^{\text {neo }}$ mutations are necessary to confirm the allelism of these mutations, the lines of evidence strongly indicate that the nucleotide substitution in the Dll3 gene is the causative mutation of the oma mouse. We, therefore, designated the symbol of the mutant allele Dll3 ${ }^{\text {oma }}$.

Dll3 is a mammalian homologue of the Drosophila Delta gene which encodes a ligand for Notch [9]. The Notch signaling pathway is an evolutionarily conserved signal transduction mechanism which plays an important role in cell fate determination during development [1]. In mammals, somite segmentation is the initial step of vertebral formation and relies on boundary formation in presomitic mesoderm which is controlled by the Notch signaling pathway $[2,11]$. Loss of function of the genes involving the Notch signaling pathway, 
including Dll1 [3, 7], Dll3 [25], Psen1 [24]), and Lfng $[10,34]$ genes, causes vertebral or somite defects in the mouse, indicating that these genes have important roles in vertebral formation. The Dlll $3^{p u}$ mutation arose during an X-ray irradiated mutagenesis at the Oak Ridge National Laboratory [16] and possesses a 4-bp deletion in the third exon of the Dll3 gene, leading to a frame shift and early truncation of the Dll3 protein [25]. The Dlll $3^{p u} / D l l l 3^{p u}$ mouse exhibits severe vertebral and rib deformities caused by a defect in formation of the morphological borders between somites and compartment boundaries within somites during embryogenesis. Similar phenotypes have also been reported in $D l l 3^{\text {neo }} / D l l 3^{\text {neo }}$ knockout mice [8]. The morphological features of $D l l 3^{\text {oma }} / D l l 3^{\text {oma }}$ are indistinguishable from those of $D l l 3^{p u} / D l l l 3^{p u}$ and $D l l 3^{\text {neo }} / D l l 3^{\text {neo }}$ mice suggesting that Dll $3^{\text {oma }}$ is a null allele of the gene as in the case of $D l l l 3^{p u}$ and Dll3 ${ }^{\text {neo }}$. However, breeding data of the Dll ${ }^{\text {oma }} / D l l 3^{\text {oma }}$ mice showed some differences between $D l l 3^{\text {oma }} / D l l 3^{\text {oma }}$ and $D l l l 3^{p u} / D l l l 3^{p u}$ or $D l l 3^{\text {neo }} / D l l 3^{\text {neo }}$ mice. As shown in Table 1, no evidence for embryonic or neonatal lethality was observed in the $\mathrm{Dll} 3^{\text {oma }} / \mathrm{Dll} 3^{\text {oma }}$ mice, while increased embryonic and neonatal mortality have been reported in Dlll $3^{p u} / D l l l 3^{p u}$ and $D l l 3^{\text {neo }} /$ $D l l 3^{\text {neo }}$ mice, respectively $[8,25]$. These differences might result from differences in the genetic background of the strains bearing these mutant alleles. Alternatively, the different types of mutations may cause the differences in mortality. The mutation in the Dllzoma allele is a single base substitution which causes an amino acid substitution, while those of Dlll $3^{p u}$ and $D l l 3^{\text {neo }}$ are a frame shift mutation and replacement of the gene, respectively, which result in complete loss of function of the gene. The mutant protein of the Dll3 $3^{\text {oma }}$ allele with the amino acid substitution may have residual activity of the D113 protein which decreases the embryonic and neonatal mortality.

Mutation in the DLL3 gene was reported in human SCD patients which is characterized by multiple vertebral segmentation defects and rib anomalies [5, 32]. SCD is a group of disorders comprised of sporadic and familial types with autosomal dominant or autosomal recessive inheritance. At least 15 distinct mutations of the DLL3 gene have been reported in patients of the autosomal recessive type of SCD. In addition to SCD, a large number of syndromes showing congenital malformations of vertebrae have been reported in human, but the causes of most of these syndromic conditions are unknown. The formation of vertebrae is one of the most important developmental processes in vertebrates and various types of vertebrae malformation can be caused by either altered function of specific genes or environmental factors during embryonic development. The Dll3 ${ }^{\text {oma }} / D l l 3^{\text {oma }}$ mice will be good animal model for studying the developmental process of vertebrae formation and the pathogenesis of human vertebrae malformations.

\section{References}

1. Artavanis-Tsakonas, S., Rand, M.D., and Lake, R.J. 1999. Notch signaling: cell fate control and signal integration in development. Science 284: 770-776.

2. Barrantes, I.B., Elia, A.J., Wunsch, K., De Angelis, M.H., Mak, T.W., Rossant, J., Conlon, R.A., Gossler, A., and de la Pompa, J.L. 1999. Interaction between Notch signalling and Lunatic fringe during somite boundary formation in the mouse. Curr. Biol. 9: 470-480.

3. Beckers, J., Schlautmann, N. and Gossler, A. 2000. The mouse rib-vertebrae mutation disrupts anterior-posterior somite patterning and genetically interacts with a Delta1 null allele. Mech. Dev. 95: 35-46.

4. Bordo, B., and Argos, P. 1991. Suggestions for "safe" residue substitutions in site-directed mutagenesis. J. Mol. Biol. 217: 721-729.

5. Bulman, M.P., Kusumi, K., Frayling, TM., McKeown, C., Garrett, C., Lander, E.S., Krumlauf, R., Hattersley, A.T., Ellard, S., and Turnpenny, P.D. 2000. Mutations in the human Delta homologue, DLL3, cause axial skeletal defects in spondylocostal dysostosis. Nature Genet. 24: 438-441.

6. Cantu, J.M., Urrusti, J., Rosales, G., and Rojas, A. 1971. Evidence for autosomal recessive inheritance of costovertebral dysplasia. Clin. Genet. 2: 149-154.

7. de Bellard, M.E., Ching, W., Gossler, A., and BronnerFraser, M. 2002. Disruption of segmental neural crest migration and ephrin expression in Delta-1 null mice. Dev. Biol. 249: 121-130.

8. Dunwoodie, S.L., Clements, M., Sparrow, D.B., Sa, X., Conlon, R.A., and Beddington, R.S. 2002. Axial skeletal defects caused by mutation in the spondylocostal dysplasia/ pudgy gene $D l l 3$ are associated with disruption of the segmentation clock within the presomitic mesoderm. Development 129: 1795-1806.

9. Dunwoodie, S.L., Henrique, D., Harrison, S.M., and Beddington, R.S.P. 1997. Mouse Dll3: a novel divergent Delta gene which may complement the function of other Delta homologues during early pattern formation in the mouse embryo. Development 124: 3065-3076.

10. Evrard, Y.A., Lun, Y., Aulehla, A., Gan, L., and Johnson, R.L. 1998. lunatic fringe is an essential mediator of somite segmentation and patterning. Nature 394: 377-381.

11. Forsberg, H., Crozet, F., and Brown, N.A. 1998. Waves of 
mouse Lunatic fringe expression, in four-hour cycles at two-hour intervals, precede somite boundary formation. Curr. Biol. 8: 1027-1030.

12. Furumoto, T.A., Miura, N., Akasaka, T., Mizutani-Koseki, Y., Sudo, H., Fukuda, K., Maekawa, M., Yuasa, S., Fu, Y., Moriya, H., Taniguchi, M., Imai, K., Dahl, E., Balling, R., Pavlova, M., Gossler, A., and Koseki, H. 1999. Notochorddependent expression of MFH1 and PAX1 cooperates to maintain the proliferation of sclerotome cells during the vertebral column development. Dev. Biol. 210: 15-29.

13. Gerin, I., Veiga-da-Cunha, M., Achouri, Y., Collet, J.F., and Van Schaftingen, E. 1977. Sequence of a putative glucose 6-phosphate translocase, mutated in glycogen storage disease type Ib. FEBS Lett. 419: 235-238.

14. Grüneberg, H. 1954. Genetical studies on the skeleton of mouse. VIII. Curly-tail. J. Genet. 52: 52-67.

15. Grüneberg, H. 1955. Genetical studies on the skeleton of mouse. XVI. Tail-kinks. J. Genet. 53: 536-550.

16. Grüneberg, H. 1961. Genetical studies on the skeleton of mouse: XXIX. Genet. Res. 2: 384-393.

17. Guzzetta, V., Bonapace, G., Dianzani, I., Parenti, G., Lecora, M., Giannattasio, S., Concolino, D., Strisciuglio, P., Sebastio, G., and Andria G. 1997. Phenylketonuria in Italy: distinct distribution pattern of three mutations of the phenylalanine hydroxylase gene. J. Inherit. Metab. Dis. 20: 619-624

18. Herrmann, B.G., Labeit, S., Poustka, A., King, T.R., and Lehrach, H. 1990. Cloning of the $T$ gene required in mesoderm formation in the mouse. Nature 343: 617-622.

19. Hollander, W.F. and Waggie, K.S. 1977. Meander tail: a recessive mutant located in chromosome 4 of the mouse. $J$. Hered. 68: 403-406.

20. Hunt, H.R., Mixter, R., and Permar. 1933. Flexed tail in mouse Mus musculus. Genetics 18: 335-366.

21. Inouye, M. 1976. Differential staining of cartilage and bone in fetal mouse skeleton by alucian blue and alizarin red $\mathrm{S}$. Cong. Anom. 16: 171-173.

22. Johnson, J., Rhee, J., Parsons, S.M., Brown, D., Olson, E.N., and Rawls, A. 2001. The anterior/posterior polarity of somites is disrupted in paraxis-deficient mice. Dev. Biol. 229: 176-187.

23. Johnson, D.R. and Wallace, M.E. 1979. Crinkly-tail, a mild skeletal mutant in the mouse. J. Embryol. Exp. Morphol. 53: 327-333.

24. Koizumi, K., Nakajima, M., Yuasa, S., Saga, Y., Sakai, T., Kuriyama, T., Shirasawa, T., and Koseki, H. 2001. The role of presenilin 1 during somite segmentation. Development 128: 1391-1402.

25. Kusumi, K., Sun, E.S., Kerrebrock, A.W., Bronson, R.T., Chi, D.C., Bulotsky, M.S., Spencer, J.B., Birren, B.W., Frankel, W.N., and Lander, E.S. 1998. The mouse pudgy mutation disrupts Delta homologue Dll3 and initiation of early somite boundaries. Nature Genet. 19: 274-278.

26. Lamoril, J., Boulechfar, S., de Verneuil, H., Grandchamp, B., Nordmann, Y., and Deybach, J.C. 1991. Human erythropoietic protoporphyria: two point mutations in the ferrochelatase gene. Biochem. Biophys. Res. Commun. 181: 594-599.

27. Manly, K.F. 1993. A Macintosh program for storage and analysis of experimental genetic mapping data. Mamm.Genome 4: 303-313.

28. Morgan, W.C. 1950. A new tail-short mutation in the mouse. J. Hered. 41: 208-215.

29. Nishimura, G., Fukushima, Y., Ohashi, H., and Ikegawa, S. 1995. Atypical radiological findings in achondroplasia with uncommon mutation of the fibroblast growth factor receptor-3 (FGFR-3) gene (Gly to Cys transition at codon 375). Am. J. Med. Genet. 59: 393-395.

30. Silver, L.M. 1985. Mouse $t$ haplotype. Annu. Rev. Genet. 19: 179-208.

31. Theiler, K. 1959. Anatomy and development of the "truncate" (boneless) mutation in the mouse. Am. J. Anat. 104: 319-343.

32. Turnpenny, P.D., Whittock, N., Duncan, J., Dunwoodie, S., Kusumi, K., and Ellard, S. 2003. Novel mutations in DLL3, a somitogenesis gene encoding a ligand for the Notch signalling pathway, cause a consistent pattern of abnormal vertebral segmentation in spondylocostal dysostosis. $\mathrm{J}$. Med. Genet. 40: 333-339.

33. Yoon, J.K. and Wold, B. 2000. The bHLH regulator pMesogenin1 is required for maturation and segmentation of paraxial mesoderm. Genes. Dev. 14: 3204-3214.

34. Zhang, N. and Gridley, T. 1998. Defects in somite formation in lunatic fringe-deficient mice. Nature 394: 374-377. 